Nestor Míguez*

\title{
Conflito e liberdade: Gálatas 2:11-14 e as lutas intraeclesiásticas
}

\author{
Conflict and Freedom. Galatians 2,11-14 \\ and the intra-ecclesiastical struggles
}

\begin{abstract}
Resumo
Este artigo considera o relato que Paulo faz de seu conflito com Pedro em Antioquia e o lugar retórico que ocupa no conjunto da carta aos gálatas. Analisa os componentes narrativos e actanciais e os vincula aos temas fundamentais que se desenvolvem na epístola. Também se assinalam as diversas concepções eclesiológicas envolvidas nesse conflito. Destaca-se o vínculo com a realidade interna e externa que vivem e nas que testificam as comunidades na província da Galácia e suas particularidades demográficas.
\end{abstract}

\begin{abstract}
This article considers the Pauline narrative concerning his conflict with Peter in Antioch, and its rhetorical role in the whole of the argument of the letter to the Galatians. It analyzes the narrative and actuarial elements of the text and relates them with the fundamental issues developed in the Epistle. The different ecclesiological understandings involved in this conflict are also indicated. It emphasizes the links with the internal and external realities in which the faith communities in Galatia, with their particular demographic situation, live and bear their witness.
\end{abstract}

\section{O contexto da carta}

A carta de Paulo aos gálatas é um verdadeiro mostruário de todas as alternativas que ocorrem na vida de uma comunidade de fé. Já

* Néstor Míguez é professor do ISEDET de Buenos Aires, Argentina. Doutor em Teologia e formação superior em Antropologia social e política; Presidente da Federação Argentina de Iglesias Evangélicas. E-mail: nestormiguez@gmail.com. 
outros artigos deste mesmo número de RIBLA se encarregam de registrar muitas delas, positivas ou não. Neste artigo nos toca lidar com uma situação de conflito interno, que não pode se separar de todas as outras circunstâncias, internas e externas, nas quais se desenvolve a vida da comunidade.

Poder-se-ia dizer que há três aspectos em jogo: por um lado Paulo tem a particular missão de apresentar o evangelho do Messias Jesus aos gentios $(1: 16 ; 2: 2,8-9)$. Por outro, aparece a figura de Pedro, tomado como verdadeira coluna da Igreja (2:9), reconhecido assim pelo próprio Paulo, além da disputa que agora passamos a considerar; o papel de Pedro aparece vinculado ao de Tiago "o irmão do Senhor", também mencionado nos encontros anteriores de Paulo com os apóstolos em Jerusalém (1:19), que aparece como a cabeça dessa comunidade. E ainda que não seja mencionado explicitamente no contexto da narrativa, o terceiro componente são os próprios receptores da carta, que devem ver nesse conflito os debates que os afetam. Cada um deles exercerá um papel diferente nos acontecimentos que esses versículos descrevem.

Contudo, além do fato de que há em jogo claramente diferenças pessoais e de personalidade, também há considerações que chamaríamos de ordem teológica, missional, de costumes, de relação com o meio externo, de construção da vida comunitária. 0 que está em discussão é, verdadeiramente, o núcleo do pensamento e compreensão que Paulo tem da mensagem do evangelho de Jesus em sua projeção universal e as diferenças substanciais com uma visão que está, fundamentalmente, apegada a manter um acúmulo de tradições próprias do judaísmo imperante naquele momento.

É necessário ter clareza nisto: a fé de Israel conheceu ao longo de sua história distintos momentos quanto à configuração de seu éthos religioso e político, de suas convicções centrais, formas de adoração, tendências internas quanto à conformação do Estado, compreensão de seu próprio lugar, modos de relação com seu entorno. 0 que se reflete na carta como a posição de Tiago está vinculado, até onde é possível perceber, ao judaísmo do Segundo Templo (como se pode ver nos livros de Esdras e Neemias, que descrevem como se concebeu o judaísmo dos que retornaram), quando tomaram forte impulso questões de identidade, pureza e certa teologia da Torá, disputada inclusive por alguns dos profetas de seu próprio tempo (por exemplo, o chamado "Trito-Isaías"; veja-se especialmente os capítulos 58-59). Também se deve assinalar que o judaísmo na época de Jesus e Paulo tem seus mais característicos 
representantes em quem formava o partido fariseu. Mas não era essa a única forma de entender a fé de Israel pelos próprios israelitas daquele tempo. Além dos samaritanos, que também reclamavam descendência de Jacó (Jo 4: 12), numerosos grupos dissidentes apresentavam outras posições teológicas. Hoje conhecemos melhor as perspectivas da comunidade de Qumran graças aos chamados "rolos do Mar Morto". Havia uma diversidade de grupos messiânicos apocalípticos, com distintas tendências também entre eles. A diáspora conhecia estas divisões e, inclusive, é possível pensar que haveria ainda mais variantes entre os distintos grupos da dispersão, que nos deixaram evidências históricas a respeito.

Certamente não podemos afirmar, como se fez quase sem matizes em outros tempos, que o conflito está dado pelos chamados "judaizantes” (de ioudaizein -Gl 2:14, única ocorrência no Novo Testamento). Mas, sua importância radica não em seu judaísmo, mas, sim como símbolo e modo de qualquer imposição legalista que ameace a liberdade. Por isso, todo o peso argumentativo da carta aos gálatas está em grande medida provocado pelo conflito que aqui se expõe. Eu me atreveria a afirmar que inclusive a carta aos Romanos, escrita provavelmente pouco tempo depois, é um prolongamento, em outros termos e com outra maturidade argumentativa, dos mesmos componentes que geraram esse conflito, ainda que ali se prescinda de nomes próprios; fala-se de "fortes" e "fracos" (Rm 14; 15).

\section{Origem do conflito}

A incorporação de pessoas provenientes de fora do judaísmo dominante foi fonte de problemas e mal-entendidos desde os começos da fé cristã. A relação de Jesus com os samaritanos, afirmada por João (4:40-43), admitida por Lucas (17:16) e negada por Mateus (10:5) mostra as distintas atitudes que se deram, possivelmente, durante o ministério de Jesus e, seguramente, no tempo imediatamente posterior. O conflito toma uma feição maior a partir da missão paulina.

Como já se notou, a corrente hegemônica no judaísmo da Judeia (e talvez nem tanto na Galileia, apesar de ter sido influente também ali) estava dominada pela concepção que podemos ver em Neemias: pureza étnica, circuncisão, estrito cumprimento da lei, inclusive da chamada "tradição oral" sobre leis de pureza. As questões dietéticas, a guarda do sábado e outras festas e a pureza ritual tinham papel decisivo na ma- 
nutenção da identidade, especialmente em confronto com os chamados "gentios". 0 dado da circuncisão não é menor: podiam ser cumpridas todas as outras exigências, mas, sem aquela tudo resultava insuficiente, como era o caso dos chamados prosélitos ou "tementes a Deus". Pelo contrário, um judeu circuncidado, apesar de falhar no cumprimento de alguns outros rituais, seguia sendo judeu (embora houvesse exceções e podiam ocorrer expulsões da sinagoga).

É possível que não fosse essa a agenda de Jesus, já que todos os evangelhos registram confrontos com fariseus sobre vários desses pontos. Mas, também, é possível ver que parte dos seguidores do Cristo de Nazaré a adotou, ao menos parcialmente. Se o Messias é judeu -argumentam- é necessário manter as marcas do pacto de Moisés para ser incluído nele e, a partir daí, tomar o caminho indicado, receber a redenção anunciada e produzida.

Nesse contexto dá-se o enfrentamento entre as posições que sustentam Paulo e Pedro/Tiago. Ademais, como veremos mais detalhadamente abaixo, incidem outros fatos que afetam esse episódio. Um é o lugar do judaísmo no Império Romano, que o considerava religio licita, para o qual havia algumas normas específicas (permitir que os escravos judeus guardassem o sábado e cumprissem outras leis de pureza; em vez de render culto "à divindade de César" era permitido render culto ao seu Deus "rogando por César"). Isso não impedia que os judeus fossem considerados um povo estranho, objeto de discriminação, ofensas e, que esta tensão, alcançasse formas de expressão violenta em algumas oportunidades, especialmente nas politeia (bairros judaicos da diáspora grega). 0 sentimento e a atitude antijudaica ${ }^{1}$ podem ser vistos em vários textos da época.

Outro fator a considerar é a situação particular do povo gálata no Império romano: por causa da relação com outros povos gauleses, eram considerados parte do "inimigo vencido", sob a imagem de um povo derrotado e escravizado -daí o peso da palavra "escravo" em toda a argumentação da carta ${ }^{2}$.

\footnotetext{
Evito usar a expressão "antissemita" porque parece reduzir a condição de semita só ao povo de Israel. Hoje em dia vemos prejuízos antissemitas frente a outros povos que também são semitas (árabes, palestinos), muitas vezes lamentavelmente instigados por outros semitas, inclusive por certos grupos judaicos. A contradição inclui o próprio dicionário da Real Academia que tem uma ampla definição de semita (tradicional, étnica, linguística), mas, reduz o significado de "antissemita" a "inimigo de judeus".

Este dado é uma importantíssima chave hermenêutica, como foi estudada exaustivamente por Kahl (2014).
} 


\section{0 relato da situação}

O conflito entre Paulo e Pedro, segundo o relato de Gálatas (cuidadosamente omitido em Atos), é marcado na narrativa das relações que Paulo deve resolver para evitar que sua missão aos gentios quebrasse a frágil unidade da nascente igreja. Essa unidade não devia ser uniformidade: as múltiplas origens, as diferenças culturais e étnicas, as distintas percepções teológicas e modos de vida podiam e deviam ser respeitados, sempre que não afetassem o testemunho e a ética do novo caminho messiânico. A unidade não era sequer de condução - a rebeldia de Paulo ante Pedro o demonstra (imagine-se um missionário questionado reprendendo o papa na cara por sua conduta). A unidade se refletia no encontro e coerência na superação do antagonismo, sem desconhecer a diversidade de situações.

Por isso Paulo defende seu ministério e a especificidade dele. A origem de seu apostolado não é a mesma que a de Pedro ou de Tiago (que são também diversos entre si) nem depende deles mesmos. 0 âmbito e as dificuldades que se impõem são distintos. Mas, se aos problemas e tensões que apresenta a ideia e a realidade de um messias redentor, crucificado e ressuscitado, um Deus único, sem imagem nem sacrifícios, uma Escritura profética, ante os povos "pagãos" que os desconheciam, se agrega o fato de que os conversos devem se "judaizar", a dificuldade aumenta e termina por negar a mesma raiz do evangelho libertador que se proclama. Isso não significa descompromisso com a matriz hebraica desse evangelho, mas, obriga a que essa matriz seja revisada e ressignificada à luz da dimensão universal que adquire o caminho de Jesus. A discussão tem que ver com o alcance, justamente, dessa revisão e suas implicações para a fé.

Não nos deteremos na comparação do relato do encontro em Jerusalém, como é descrito na carta, com o de Atos 15. Sobre isso há abundante literatura na maioria de comentários bíblicos tanto de um livro como de outro. Para o objetivo de nosso estudo a primeira pergunta a fazer-se é: por que Paulo inclui na carta o relato desse episódio que, posteriormente a esse acordo, desata o conflito ocorrido anos antes em Antioquia? Que função argumentativa e retórica cumpre o episódio no todo da carta?

Os dois primeiros capítulos da carta aos gálatas são particularmente autorreferenciais. Paulo defende sua condição de apóstolo de Jesus Messias, sem necessidade de autorizações prévias, sua condição 
de eleito de Deus, a especificidade de seu ministério, seus acordos para desempenhá-lo livremente, seu compromisso com os pobres no cumprimento do pedido que lhe tinha sido feito. A carta provê (junto com Fp 3) mais dados autobiográficos que na maioria de suas cartas. E nesse contexto faz menção dessa confrontação com Pedro e, indiretamente, com Tiago. A partir daí introduz o tema da justiça, que é pela fé e não pela lei, o que constituirá o coração argumentativo do resto da epístola. Assim, cumpre com vários propósitos: passa do biográfico ao teológico, do pessoal ao comunitário e, ao mesmo tempo, reafirma sua autoridade como apóstolo em um enfrentamento "de igual a igual" com Pedro. Ademais, marca indiretamente sua concepção de igreja: unidade sem hierarquias, comunhão sem exclusões, justiça e liberdade em vez de pureza e legalidade.

Primeiro há que destacar, então, na narração do episódio, o lugar do enfrentamento: estamos em Antioquia, quer dizer, os começos da expansão da nascente fé messiânica fora do território de Israel. Por certo a comunidade judaica em Antioquia da Síria (Antioquia sobre o Orontes) era uma das mais numerosas da diáspora. Mas, por sua vez, segundo algumas fontes históricas, havia uma evidente tensão com a população grega do lugar, o que motivou vários enfrentamentos ao longo do século primeiro (PAUL, 1982, p. 142-3). Apesar disso, constrói-se ali uma comunidade de crentes em Jesus que esteve integrada por pessoas de origem judaica, outras de origem pagã e que foi a primeira na qual se usa o termo cristãos - segundo Atos 11:19-26. É de notar que essa integração teria sua origem a partir de judeus diaspóricos convertidos em Jerusalém e, portanto, a presença de cristãos gentios era anterior à missão de Paulo.

A chegada de Pedro a Antioquia e sua presença na comunidade (ignorada por Atos) em princípio não produzem uma ruptura em sua dinâmica e suas práticas, mas, sim a chegada de emissários de Tiago, que convencem Pedro, e outros membros judeus da comunidade, inclusive Barnabé, a separar-se para respeitar as leis judaicas de pureza na comensalidade. É essa "volta atrás" que escandaliza Paulo e que provoca sua reação, a tal ponto que utiliza a palavra hipócrita (2:13b) que, segundo o Evangelho de Mateus, foi usada por Jesus para caracterizar os fariseus (Mt 23:13-29).

Apesar de o texto não indicar explicitamente que isso afetou o que hoje chamaríamos "unidade eucarística", pode-se supor que, dado que a Ceia do Senhor provavelmente estava unida à ceia agápica, a separação 
de mesas também a afetaria. Nisso há comparação com a situação em Corinto. Ali a discriminação parece dar-se por razões econômicas (1Co 11:20-23) e termina por trazer indignidade a quem participa "sem discernir o corpo do Senhor" (11:29), isto é, sem contemplar a unidade da igreja (o corpo de Cristo é um só -1Co 12:12). Na igreja de Antioquia a separação ocorreria por motivos étnicos, o que é igualmente grave.

Paulo atribui essa conduta ao "temor aos judeus" (Gl 2:12d). Não é claro a que isso pode se referir. Uma possibilidade é que seja aos judeus da própria comunidade, que estariam seguindo a direção de Tiago. Parece pouco provável, já que eles mesmos haviam proclamado o Evangelho entre os gentios e praticavam a comensalidade comum antes desse episódio. Por outro lado, isso não teria porque provocar medo em pessoas como Pedro e Barnabé, com uma liderança tão forte como a do "irmão do Senhor". Mais provável é que se refira à comunidade judaica antioquenha não cristã, que podia acusar os cristãos de haver deixado de praticar uma religio licita (sejam suas crenças anteriores ou sua pertença à sinagoga) e haver caído em uma superstitio, o que era condenado pelas leis romanas. Paulo pode fazer referência a isso em Gl 6:13; obrigar conversos a circuncidar-se pode ser considerado um triunfo do judaísmo hegemônico.

O certo é que a discrepância dá lugar a uma dura altercação, cujo resultado prático desconhecemos. 0 que sabemos é o resultado teológico, pois a situação que se deu parcialmente em Antioquia agora se repete nas igrejas da Galácia. E isso provoca novamente a reação de Paulo e o leva a aprofundar sua teologia da liberdade e da graça com a outra forma, diferenciada da lei, da justiça divina (MÍGUEZ, 2010, p. 80-90).

\section{Os personagens}

Pareceria redundante falar de Paulo, Pedro, Tiago, Barnabé. Todos são nomes conhecidos na trajetória neotestamentária. Todos eles deixam rastros de seu caráter em escritos a eles atribuídos dentro do cânon do Novo Testamento ${ }^{3}$. Por isso nos atemos ao lugar actancial que ocupam nesse relato.

No caso de Barnabé, além de seu destacado papel em Atos, uma antiga tradição lhe atribui a chamada "Epístola aos Hebreus". Mais tarde a literatura pós-apostólica inclui a apócrifa "Carta de Barnabé" (provavelmente datada de 130), cuja canonicidade esteve em discussão durante séculos; finalmente foi excluída. 
Sem dúvida é ninguém mais nem menos que Pedro quem é exposto como mau exemplo (papel actancial de adversário). Depois de reconhecê-lo no primeiro capítulo da epístola como alguém com quem quer estar em acordo, com quem encontrou mais de uma vez e estabelecidos, de boa maneira, os respectivos papeis e incumbências na missão, nesse episódio se vê como alguém em quem não se pode confiar. Aqui aparece como uma personalidade ambígua, influenciável e inclusive simuladora (o verbo usado em 2:13 tem sua raiz em "hipócrita"). Mais adiante Paulo assinala que Pedro como judeu é um mau judeu, já que não se atém à forma de vida judaica (2:14). Mas, agora, pressionado pelos "de Tiago" e, talvez, sua conexão com o temor ante a comunidade judaica de Antioquia, finge ater-se às normas dietéticas hebraicas.

A autoridade de Pedro é duplamente questionada: tanto em seu lugar de condução eclesial como em sua dimensão ética. A menção de Pedro tem papel não desprezível nesse episódio. Apesar de a referência ao episódio parecer uma digressão no conjunto da carta, tem uma função retórica decisiva: se o próprio Pedro foi questionado em Antioquia, se Paulo se põe como autoridade moral por cima dele a ponto de repreendê-lo, se sua conduta é reprovável, quanto mais seriam os outros agentes que nas igrejas da Galácia pretendiam introduzir a circuncisão como necessária para os conversos gentios. Se Pedro, ao separar-se dos não-judeus nas comidas, é um hipócrita, que adjetivo cabe aos que, na Galácia, querem impor a totalidade da lei judaica aos que se aproximaram do Evangelho do messias crucificado?

Mas, sem dúvida é Tiago quem aparece mais claramente como quem deforma o sentido da liberdade evangélica (papel actancial de enviado do adversário). Há uma referência em 2:4 aos que "espiam a liberdade que temos em Cristo"; embora não se faça referência direta a Tiago, tudo aponta para isso. De soslaio, Paulo também questiona sua autoridade ao dizer que Deus não faz acepção de pessoas e que "não me comunicaram nada novo" (2:6). Também, nesse caso destaca-se uma relação amigável com Tiago nas duas visitas a Jerusalém, que Paulo reconhece ter realizado (Gl 1:18-19; $2: 1 ; 9$ ) e que se quebra com esse episódio.

Embora seja duvidoso que esse Tiago seja o autor da epístola que leva seu nome, é provável que de alguma maneira reflita sua posição teológica. Assim há que reconhecer que, ao examinar-se a chamada "Epístola de Tiago", não se oculta certa tensão entre seu conteúdo e o que se destaca como a atitude dos emissários de Tiago na carta aos 
gálatas. A teologia que Tiago assume nesse caso, um cumprimento detalhado da lei, não condiz exatamente com a que aparece na mencionada epístola, em que se fala da lei da liberdade (Tg 1:25; 2:12) e que o amor ao próximo é a lei fundamental (2:8), coincidindo com o que Paulo ensina também em Gálatas (5:14) e na carta dirigida à igreja de Roma (Rm 13:9), ainda que com consequências distintas. A tensão e contraponto entre Tiago e Paulo ficam evidenciadas na literatura bíblica, mas, são de outros matizes.

A amizade de Paulo com Barnabé (papel actancial de ajudante do adversário) evita que sobre este recaia uma crítica tão dura. Barnabé "é arrastado" nessas circunstâncias a uma conduta que não seria usual nele. Barnabé partilha com Paulo, com reconhecimento de Pedro e Tiago, a missão aos gentios (2:9). Por isso é inexplicável que aceite separar-se da mesa com os gentios, a menos que fosse devido a uma pressão muito forte. Também esta breve inclusão no relato tem um poderoso efeito retórico: há quem seja levado a essa posição pela pressão social, apesar de não fazer parte de suas convicções. É necessário que reconheçam isso e possam voltar à senda da liberdade.

Finalmente o próprio Paulo se apresenta a si mesmo como o campeão de um evangelho libertador (papel actancial do protagonista/ herói). Eleito por Deus desde "o ventre de minha mãe" (adjuvante do protagonista), a graça divina o convoca mediante manifestação direta para que leve sua mensagem aos não-judeus (1:15-16). Essa mensagem é de liberdade; é o objeto da ação: assegurar a liberdade dos sujeitos, as comunidades messiânicas da Galácia. A palavra "liberdade" tem papel preponderante em toda a carta: Cristo "nos fez livres" e "à liberdade foram chamados" $(5: 1,13)$. Recordemos que ele está escrevendo a um povo que tinha sofrido sucessivos processos de escravidão (os "gálatas" haviam sido submetidos primeiro pelos gregos de Pérgamo e agora pelos romanos - ver o citado estudo de Kahl). Depois que Cristo os liberta - não econômica ou politicamente, mas simbolicamente - não tem sentido deixar-se levar a outra escravidão, a da lei. A lei não é simplesmente a lei mosaica, ou a lei romana, mas a lei como forma de vida (TÁMEZ, 1991, p. 88-92) .

Para uma personalidade decidida, como a que demonstra Paulo, para alguém que enfrentou todos os riscos pelo Evangelho, para

Também, meu estudo "Gálatas e Romanos: liberdade e justiça”" (Apresentação no Congresso Internacional SBL, Buenos Aires, julho 2015, a ser publicado brevemente), no qual estudo o tema da lei como "dispositivo". 
alguém profundamente transformado, como é ele, essa ambiguidade e inconstância na conduta de Pedro é incompreensível. É um caso de personalidade, mas, também de convicção, que está em jogo. A reação de Paulo, ademais, põe em juízo todo o construto eclesial, anula a hierarquia das relações internas. Ao mostrar que "Deus não faz acepção de pessoas" (Dt 10:17 passim) no contexto em que se debate quem é importante e quem não, está afirmando que a comunidade messiânica não reconhece hierarquias nem distinção entre seus membros, além das funções e vocações que cada um recebe. Paulo questiona as divisões que organizam a sociedade romana, com apadrinhamentos e ordens e resiste a que sejam adotadas na igreja. Isso também aparece na epístola de Tiago (cap. 2) que começa com a mesma citação veterotestamentária.

Mas, já notamos, o sujeito não nomeado em tudo isso são as próprias comunidades de fé a quem se dirige a epístola. Estão sendo submetidas a pressões de muitos lados. 0 testemunho de fé que recebem está longe de ser uniforme, além das trocas simbólicas e de vida que a mensagem evangélica produz. Esse é o risco a superar, a prova que define o conflito. Assim, em sua estratégia discursiva para superar a situação, Paulo não os trata muito bem, já que toda a carta mostra um tom irado e talvez até insultante ("gálatas insensatos" - Gl 3:1). E se bem destaca, em alguns momentos, o sentido afetuoso de sua relação com essas comunidades (4:13-16), também terá expressões quase rudes quando se refere a seus adversários (5:12).

O verdadeiro objeto aparece como corolário do relato: “Sabemos que o ser humano não recebe justiça pelas obras da lei, mas pela fé em Jesus, o Messias" (2:16a). A presença de adversários na Galácia - como a de Pedro em Antioquia - põe em risco a união da comunidade com seu Salvador e, também, a unidade interna da própria comunidade. Também põe em risco a integridade do ministério de Paulo (5:11). Vencer esse risco, manter a integridade do Evangelho e afirmar a vocação libertadora é o sentido último do relato e sua função exemplificadora no desenvolvimento da carta.

\section{O conflito na comunidade}

Qual será a repercussão desse conflito nas igrejas da Galácia? Não podemos saber com certeza. Faz alguns anos, em um evento ecumênico de leitura popular da Bíblia no Uruguai, no qual estudamos esses textos, propus como exercício escrever uma carta a Paulo, em resposta 
à epístola aos Gálatas. Os diferentes grupos apresentaram variadas respostas. Desde um mais complacente "Paulo, estamos contigo, perdoa nossas dúvidas, graças por nos contradizer e nos instruir", até um desolado "Se vocês, que são nossos evangelizadores e referências se tratam assim, que podemos nós fazer, recém-chegados e confundidos?".

Não creio que as comunidades gálatas tivessem reações muito distintas, o que talvez provocasse ainda mais as brechas internas. Temos que ter claro é que Paulo usa o incidente ocorrido em Antioquia como recurso argumentativo para enfrentar um conflito similar, mas, com outros condimentos nas igrejas da província da Galácia na Ásia Menor, sob o poder do império romano. 0 conflito nas igrejas gálatas tem outros componentes: não é só o tema da tensão entre quem provém do judaísmo e das diversas gentilidades que habitam a região ${ }^{5}$. É a pressão que esses estratos culturais exercem sobre a unidade das comunidades, na medida em que persistem como dados inconscientes em quem as recebe.

Para essas diferenças há quem proponha uma solução fácil: tornem-se todos judeus, circuncidem-se, e, já israelitas, aceitem Jesus como Messias. Mas Paulo descrê dessa solução por várias razões, que foram indicadas em outros artigos desta publicação (HINKLAMMERT, 2013). A condição de Messias crucificado e sua projeção universal se desmentem se há que aderir ao judaísmo e suas leis. Ou, para quem vive na opressão e escravidão a qualquer outro poder ou outra lei. Em 4:3 afirma que há outra escravidão que os submetia: os elementos (os princípios, segundo se traduza stoicheia) do mundo. Talvez a referência seja a alguns dos elementos religiosos das culturas prévias, ou os elementos da filosofia grega, ou as divindades romanas, que incluíam a divindade de César, muito difundida na região. Se tinham sido deixados para trás, se tinham sido superados esses componentes de sua servidão, por que agora têm de submeter-se a outros, ainda que provenham do judaísmo legalista?

\footnotetext{
Devemos ter em conta que embora a tendência seja unificar tudo sob o nome de "gentios" ou "não-judeus", na realidade a população da região tinha sucessivas capas demográficas, cada uma com seus próprios costumes, que haviam decantado com o correr dos séculos. Às tribos vernáculas originais deve-se somar a migração gaulesa (que dá nome à província), as sucessivas presenças grega e romana, estas últimas como conquistadores. De maneira que encontramos, ao menos, quatro estratos populacionais superpostos, com distintos costumes e culturas (incluindo matizes religiosos diferenciados). De todos eles os dois primeiros, habitantes originais e os migrantes gauleses eram os que sofriam maior opressão e exploração, por parte do Império, que havia reduzido muitos de seus componentes à escravidão.
} 
A unidade das comunidades (que não deve ser entendida em sentido institucional, mas em sua prática de vida) não se obtém fazendo que todos (e todas, ainda que a circuncisão afete somente os varões) adotem costumes e modo religioso de uma parcialidade: só Cristo produz essa unidade que supera as diferenças $(3: 28)^{6}$. Aqui se põe em jogo a dignidade humana de todos e todas. Os vencidos são resgatados, a esperança se afirma; passa-se a desejar que a corrupção e a vontade de opressão pelos poderes que dominam o mundo sejam contidas. 0 amor se impõe como norma de vida, o Espírito guia a fé dos crentes. 0 novo Israel de Deus (6:16) se constitui como povo, não a partir da lei, mas, a partir do exercício da liberdade, a misericórdia e a paz. 0 mundo é crucificado, enquanto Cristo ressuscita para uma nova criação (6:14-15).

\section{O conflito e o entorno}

Um último parágrafo para outra dimensão desse conflito. Já notamos que essa situação não ocorre em um vazio, mas, em meio do poder do Império Romano e em uma província particularmente marcada pela opressão, em meio a um povo que simbólica e praticamente era considerado o adversário derrotado por excelência. Gauleses e gálatas eram o mesmo: povo a vencer e escravizar, bárbaros e rebeldes a civilizar, remanescentes demoníacos de um tempo mítico, que foram vencidos pelos deuses da sabedoria. Assim eram representados na propaganda romana.

O judaísmo também era objeto de similares considerações: um povo estranho, de costumes incompreensíveis, obstinado por um único Deus zeloso, embora não os resguardasse em sucessivas quedas. 0 Messias Jesus veio libertar ambos, entende Paulo. E essa libertação começa pelo sentido da própria dignidade, que não depende de uma lei nem de marcas corpóreas. As marcas que Paulo leva não é apenas a da circuncisão (ainda que a tivesse), mas, as dos padecimentos por Cristo (6:17). O que constitui o povo, além das diferenças que subsistem, é a justiça de Deus que se manifestou em Jesus, e o poder confiar nela.

${ }_{6} \quad$ É interessante notar que dos três componentes das diferenças assinaladas em 3:28, os dois primeiros têm claras referências externas na epístola: etnia e condição social; o terceiro, de género, não aparece explícito. Mas, evidencia-se a exigência de circuncisão, que só afeta homens: se as mulheres não necessitam (nem podem) circuncidar-se para participar da comunidade, por que devem fazê-lo os varões? A marca étnica é também uma marca de gênero que acaba incluída na unidade com o Messias. 


\section{Referências}

KAHL, Brigitte. Galatians Re-Imagined: Reading with the Eyes of the Vanquished. Minneapolis: Augsburg Fortress Publishers, 2014.

HINKELAMMERT, Franz. La maldición que pesa sobre la ley. Las raíces del pensamiento crítico en Pablo de Tarso. San José de Costa Rica: Ediciones Arlekín, 2013.

MÍGUEZ, Néstor. La gracia en la teología paulina: profecía, política y economía, Estudos de Religião, v. 24, n. 39, p. 80-90, 2010.

PAUL, André. El Mundo judío en tiempos de Jesús: historia política. Madrid: Ediciones Cristiandad, 1982.

TAMEZ, Elsa. Contra toda condena. La justificación por la fe desde los excluidos. San José de Costa Rica: DEI, 1991.

Traduzido por Paulo Sergio de Proença 